\title{
Review on Cylinder Head Design for Swirl Optimization
}

\author{
Prashant Nimba Pakale \\ Mechanical Engineering Research Student \\ D. N. Patel COE Shahada \\ Dist Nandurbar, Maharashtra, India.
}

\author{
Dr. D. M. Patel \\ Mechanical Engineering Dept. \\ Associate Professor \\ D. N. Patel COE Shahada \\ Dist Nandurbar, Maharashtra, India.
}

\begin{abstract}
Internal combustion engines have been a relatively inexpensive and reliable source of power for applications ranging from domestic use to large scale industrial and transportation sectors in most of the twentieth century. Motion of charge in cylinder of internal combustion engines is a key factor that governing the fuel-air mixing and burning rates in combustion of diesel engines. A good swirl promotes the fast combustion and improves the efficiency. The engine should run at low speeds, in order to have low mechanical losses and fast combustion, enabling good combustion efficiency. Therefore to produce high turbulence prior to combustion within the cylinder, swirl induced by the inlet channel within the cylinder head will be helpful. The need of automobile vehicles, still satisfying demands for high performance, necessitates immense efforts to develop innovative engine concepts and produce less emission. The fluid flow analysis plays an important role for airfuel mixture preparation to obtain the better engine combustion, performance and efficiency. Due to the extreme conditions inside a typical IC-engine (high combustion temperatures and pressures, precipitation of soot and other combustion products, etc.) experimental techniques are sometimes limited in approaching the above mentioned problem. Alternatively, numerical Techniques (Computational Fluid Dynamics, CFD) offer the opportunity to carry out repetitive parameter studies with clearly defined boundary Conditions in order to investigate various configurations.
\end{abstract}

Keywords-Cylinder head, Swirl, CFD.

\section{INTRODUCTION}

Now days, In Automobile sector, IC engines have been a relatively inexpensive and reliable source of power for applications ranging from domestic use to large scale industrial and transportation sectors in most of the twentieth century. Direct-injection diesel engines, having the evident benefit of higher thermal efficiency than all other engines, hence it served for both light- duty and heavy-duty engines Motion of charge in cylinder of internal combustion engines is a key factor that governing the fuel-air mixing and burning rates in combustion of diesel engines. A good swirl promotes the fast combustion and improves the efficiency. The engine should run at low speeds, in order to have low mechanical losses and fast combustion, enabling good combustion efficiency. Therefore to produce high turbulence prior to combustion within the cylinder, swirl induced by the inlet channel within the cylinder head will be helpful. The need of automobile vehicles, still satisfying demands for high performance, necessitates immense efforts to develop innovative engine concepts and produce less emission. In the evaluation of Internal Combustion Engine the performance, efficiency and emission formation depends on the formation of air-fuel mixture inside the engine cylinder. The fluid flow analysis plays an important role for air-fuel mixture preparation to obtain the better engine combustion, performance and efficiency. Due to the extreme conditions inside a typical IC-engine (high combustion temperatures and pressures, precipitation of soot and other combustion products, etc.) experimental techniques are sometimes limited in approaching the above mentioned problem. Alternatively, numerical Techniques (Computational Fluid Dynamics, CFD) offer the opportunity to carry out repetitive parameter studies with clearly defined boundary Conditions in order to investigate various configurations. After of clean observation of all the Research in swirl motion plays an import role to increases in engine performance as well as decrease the emissions.

\section{LITERATURE SURVEY}

R Ramachandra et al. (2016) discussed about the analysis of different manifolds in the previous sections; analysis is extended to compare the effect of different manifold Configurations on flow structure. The helical spiral manifold geometry creates higher velocity component (W/Vp) inside the combustion chamber at the end of compression stroke. Swirl ratio inside the cylinder and turbulent kinetic energy are higher for spiral manifold. Volumetric efficiency for the spiral helical combined manifold is $10 \%$ higher than that of spiral manifold. The summary of the comparison is that Helical-spiral combined manifold creates higher swirl inside the cylinder than spiral manifold. Helical manifold provides higher volumetric Efficiency. Helical-spiral combined manifold provides higher mean swirl velocity at TDC of compression. In-cylinder calculations of the intake and compression strokes of a DI Diesel engine equipped with two intake valves were carried out. The resulting flow field was analyzed for different combustion chamber shapes and compared with a limited number of measurements. [1]

Bandi.Ramanjulu, et al. (2015) have studied about the analysis of different manifolds in the previous sections, analysis is extended to compare the effect of different manifold Configurations on flow structure. The helical-spiral manifold geometry creates higher velocity component (W/Vp) inside the combustion chamber at the end of compression stroke. Swirl ratio inside the cylinder and turbulent kinetic energy are higher for spiral manifold. Volumetric efficiency for the spiral helical combined manifold is $10 \%$ higher than that of spiral manifold. The 
summary of the comparison is that Helical-spiral combined manifold creates higher swirl inside the cylinder than spiral manifold. Helical manifold provides higher volumetric Efficiency. Helical-spiral combined manifold provides higher mean swirl velocity at TDC of compression. Incylinder calculations of the intake and compression strokes of a DI Diesel engine equipped with two intake valves were carried out. The resulting flow field was analyzed for different combustion chamber shapes and compared with a limited number of measurements. [2]

K.Raj Kiran, et al. (2017) have focused on cylinder head design and make the lead angle turning by 300 and lastly conclusions were drawn on performance characteristics of single cylinder, four strokes, and water-cooled engine while running the engine with standard and modified inlet manifold of $90 \mathrm{o}$ for single open and both open conditions that Brake thermal efficiency increases by $1.87 \%$ for the 30 o modified flow as compared to the standard flow. NOx emission is reduced in the modified condition by $57.6 \%$ as compared to that of standard condition. For modified flow condition HC content increase by $21.2 \%$ than that of standard condition. Increase in Smoke emission by $4.65 \%$ for the modified condition to the standard condition is the important condition to look out. The cylinder pressure reduced by $19.9 \%$ in the modified flow condition compared to that of the standard and there is reduction in the heat release by $12.15 \%$ for the modified flow to that of the standard flow.[3]

Lucas Konstantinoff et al. (2017) have explained about cylinder heads with two different valve-seat designs were tested on a static flow bench to acquire comparable data describing flow characteristics. Data on the air flow rate and angular momentum generated by the inlet port was used to calculate the flow and swirl coefficients and describe the cylinder heads static-flow performances. The static flow bench results were compared to results from PIV analysis conducted at an optical test bench for the visualization of flow and velocity patterns. The benchmarked cylinder heads were mounted on a state-of-the-art biogas CHP unit, engine performance was measured and the combustion was analyzed with an indication system. Through all loads, maximum cylinder pressure and correlating combustion rates were higher with the new valve-seat design. Additionally, the overall combustion velocity did not seem to be affected by the load at which the engine was run. This observation means that the new sickle-shape design is likely to improve burning velocities for all stationary-operated gas engines of similar size. Further research will include a detailed consideration of partial load operation, particularly at $50 \%$ of the nominal power output. These already-planned experimental investigations are expected to show the degree of influence of the swirl motion on full- and partial-load operation. They have proven that a goal-orientated optimization of the charge motion has the potential to improve internal combustion and, hence, thermal efficiency.[4]

Pankaj N.Shrirao et al. (2015) studied about the configuration of cylinder head with three oval shape dimples enhances the turbulence and hence results in better air-fuel mixing process. As a result, the thermal efficiency is increased and BSFC and exhaust emissions are reduced. The maximum enhancement in brake thermal efficiency, volumetric efficiency for engine with three oval shape dimples on cylinder head were found to be $4.6 \%, 0.91 \%$ respectively at $2.5 \mathrm{~kW}$ load compared to engine with conventional cylinder head. It is observed that $6.66 \%$ of reduction in bsfc at $2.5 \mathrm{~kW}$ load engine with three oval shape dimples on cylinder head compared to engine with conventional cylinder head. The exhaust gas temperature is lower for diesel engine with one and three oval shape dimples on cylinder head than engine with conventional cylinder head. It is observed that $5.32 \%, 4.87 \%$ and $2.9 \%$ of reduction in $\mathrm{HC}, \mathrm{CO}$ and $\mathrm{NOx}$ emissions respectively at $2.5 \mathrm{~kW}$ load for engine with three oval shape dimples on cylinder head compared to engine with conventional cylinder head. The results indicate that inlet manifold with three oval shape dimples on cylinder head is identified as optimum configuration based on performance as well as exhaust emissions of diesel engine.[5]

J Benajes et al. (2004) investigated in combustion chamber and optimum swirl value has been found for each engine operating mode. However, it can be concluded that there is no single optimum value of swirl ratio for the whole engine operating range, and matching the level of swirl with other parameters is a task that also depends on the combustion chamber geometry and injection characteristics. Nevertheless, the results obtained here can shed light on the swirl effects on diesel engine combustion and exhaust emissions over a wide range of engine operating conditions.[6]

H. Mohamed Niyaz1 et al. (2014) have discussed about simulation approach which is carried out for the intake port to have optimized swirl torque which enhance the maximum performance of the internal combustion engine. Simulation results shows the intake port gives lower swirl ratio and high flow coefficient for the better performance of the engine. More deviation is coming at lower valve lift conditions, because flow bench system, there is a possibility of cumulative calibration error and type of turbulence model is used to resolve boundary layer at the valve seat area and CAD may have little deviation from flow bench setup. CFD and flow bench measurement for the swirl ratio is closely matching with each other. Though the paddle wheel speed is different from CFD analysis. But it is having little deviation at the high valve lift, because $2 \mathrm{D}$ monitor plane is used in CFD in-place of paddle wheel arrangement. [7]

M D Raj Kamal et al. (2017) have studied on optimization of inlet air to the engine can be done by means of inlet poppet valves. CFD simulation can advise better results. Masking of inlet valves improves swirl rate and intern brake thermal efficiency of the engine. Fins also increase the swirl rate and hence we can get better thermal efficiency. The swirl helps to improve a performance and reduce the exhaust emissions. Pollution levels are also decreased with both valves when compared to the conventional valve. The manufacturing cost of masks and fins are less and can easily prepare.[8]

Zhen Lu, et al. (2013) have studied based on the existing three-dimensional design software and the defined parameters, a parametric design method for a singletangential-port design was developed, and the twin port for a four-valve diesel engine can also be obtained by utilizing an assembly of parametrically designed single tangential ports. Also, not only the performance of the single port but also the performance of the twin port can be optimized by adjusting 
the values of the defined parameters. The numerical simulation results of the parametric design method are compared with relevant experimental work. Conclusions are derived that both experimental and numerical simulation results showed that the newly developed design method can help to optimize the tangential port design to achieve an ideal flow coefficient and ideal swirl ratio. Most of the newly defined port parameters do not have a noticeable impact on the mean flow coefficient. The mean swirl ratio is sensitive to several design parameters, such as Av, Ab and Hv. The mean swirl ratio varies inversely with the values of $\mathrm{Av}, \mathrm{Ab}$ and $\mathrm{Hv}$ and reaches a maximum at $\mathrm{Ah}=90$. The flow coefficient is mainly influenced by the port flow area. The influence of the port surface (in particular, the surface of the port outlet) on the flow affects the swirl intensity significantly. The comparison between the experimental results and numerical simulation shows that the newly developed design method is useful for designing a new intake port with good performance.[9]

Arjun Garg et al. (2017) have summarized the in-cylinder charge motion often plays a dominant role in preparation and conveyance of fuel mixture in the engine. The production of high turbulence intensity is one of the most important factors for stabilizing the ignition process and fast propagation of flame, especially in the case of lean-burn combustion. This paper outlines the process of design optimization of piston head using Computational Fluid Dynamics (CFD). The parameters that were varied were the location, shape, size and number of the depressions or crowns over the piston head. The basis of optimization was flow uniformity throughout the component, prevention of separation of air flow in the piston head geometry.[10]

Jorge MARTINS et al. (2009) have created a computer model in GAMBIT was used for FLUENT simulations. Simulations were made to measure the swirl on a spark ignition internal combustion engine. Looking at the cross sections of the three tests (inlet valve opened at $1.5,2.0$ and $2.5 \mathrm{~mm}$ ), it can be seen that the progress of the swirl with the different valve lifts is the same. The swirl starts at cross section A-A in the centre of the cylinder. In cross section B-B a second swirling starts to settle pushing the main swirl away from the centre of the cylinder. This second swirling flow stays on approximately the same location until the flow reaches the bottom of the cylinder. When looking at the values of the swirl, an increase of valve lift results in a decrease of both the swirl number and the swirl component. The best results for swirl are reached for a valve lift of $1.5 \mathrm{~mm}$. This is as expected, because with a valve lift of $1.5 \mathrm{~mm}$ there is less area between valve and valve seat where the air can pass resulting in higher speed and angular momentum. Comparing the swirl number with the swirl component, the values of both numbers at the top are almost the same. This is because both numbers are calculated in the same way, but the swirl number is calculated in the centre of the swirl and the swirl component is calculated in the centre of the cylinder (axis). At the top of the cylinder the centre of the swirl is in the centre of the cylinder and thus the values are approximately the same. [11] K Vijaya Kumar, et al. (2018) emphasized with the use of swirl piston there has been an improvement in brake thermal efficiency and decrease of brake specific fuel consumption and have a remarkable decrease in exhaust emissions of $\mathrm{HC}$, NOx. Also the results obtained for advanced injection timing performance are better compared to other injection timings.[12]

Ujwal D. Patil et al. (2013) discussed about developing intake port geometry to meet the swirl ratio required to meet emission and intake ports were simulated on CFD to know velocity vectors, different flow patterns and is used to predict/improve performance. CFD simulation of intake ports and prototype testing results compared to know the compatibility of CFD tool results. The arrangement and orientation of helical and directed port have an important effect on swirl ratio and intake flow interference and different swirl value can be optimized with different valve location and layout on cylinder head further.[13]

V M Latheesh, et al. (2018) worked on the experimental results were found to be in accordance with simulation results. The CFD method can be used as a good tool for evaluating ports. After validation, it was clear that CFD software helps to reduce the number of real time experiments to be conducted to achieve the optimal port design. Position of tangential and helical port influence the swirl motion generated inside the cylinder. Conversion of existing 2 valve cylinder head to 4 valves requires a tradeoff between a lots of design parameters and may not support modern high swirl generating port layouts. [14]

Bharani Dharan R, et al. (2018) studied about cylinder head which have been developed for a high combustion pressure of around 200 bars used for $75 \mathrm{~kW} / 1$ by using CGI material. Design of Head is carried out within several design, assembly and manufacturing constraints such as to maintain a specific cylinder centre distance, four valve layout, internal EGR passage, CGI material, incorporation of various accessories, viz. manifolds, thermostat housing, cam carrier, glow plugs integrated with pressure transducer, etc. Major focuses have given on cylinder head layout, bolt Pattern, port layoutting, water jacket core optimization for flow and strength while going for the design. Various port lay out have been studied and various options have been tried out and swirling direct port with a feeder port was designed for this application. These ports were designed and developed with help of theoretical swirl requirement calculations, CFD analysis and Flow-Bench testing results.[15]

Kunjan Sanadhya, et al. (2015) did the experimental investigation of helical inlet port flow characteristics for cylinder head of Direct Injection (D.I) diesel engine. The average flow coefficient and swirl number is obtained using a paddle wheel test bench. Intake port helix parameters, i.e. distance between peripheral side wall and valve axis ' $D p$ ', width of helical section parallel to valve axis ' $\mathrm{W}$ ' and initial width of the helix 'Wh' are measured for different flow boxes for selected different bore and stroke engines. These parameters are modified and detailed analysis has been done to establish the effect on swirl number and average flow coefficient. The second part of work focused on the Computation Fluid Dynamics (CFD) to study flow velocity, flow distribution inside cylinder and to analyze effect of helix parameter change. The experimental study of combined effect of helix parameters, ' $\mathrm{W}$ ', 'Wh' and 'Dp' indicates that this modification can be initiated for improving flow 
characteristics if change required in average flow coefficient is small as compared to higher amount of change required in swirl number. The CFD analysis with this modification also shows improvement in swirl generation and flow distribution.[16]

Kumar P. Shaha, et al. (2017) have given procedure regarding the designing, operation and parameters of the swirl test rig. AVL and Ricardo swirl measuring techniques are widely used in industries for design and development of cylinder heads. It has been observed that steady state flow condition must be fulfilled for measurements to be taken. In such test rigs, it is difficult to fulfill the actual condition of real time working engine. The value of swirl is an important parameter in the design and development of inlet, exhaust ports and the cylinder heads.[17]

Shuisheng JIANG, et al. (2012) studied n order to research about the performance of diesel helical intake port, the method of steady flow test and CFD Numerical simulation was combined to do structure study. By the steady flow test, the parameters of boundary condition for simulation calculation were provided, such as the flow coefficient and swirl ratio. Based on the experiment results, CFD simulation was calculated on the three-dimensional models of intake port with the modification of center distance, valve chamber height and the valve cone angle. And the results basically analyze that the flow characteristic of intake port was affected by above three parameters. This research shows the direction of detailed design of intake port and further experiment, which can shorten development time and costs of intake port. From results they have conclude that Compared CFD software's simulation calculation with experiment on 3D model, it's found that the flow coefficients and swirls ratios are in good agreement. The CFD method can provide digital reference for the structure design and proves the feasibility of evaluation of intake port by CFD application.[18]

Jun-ichi Kawashima, et al. (1998) investigated the performance of the intake port system, steady-state flow tests were conducted in parallel with three-dimensional computations. In conducting the steady-state flow tests, it was found that a paddle wheel flow sensor was not suitable for evaluating the characteristics of the high-swirl port and that it was necessary to use an impulse swirl flow meter. An automatic mesh generator that can efficiently produce computational meshes for the helical port, the tangential port and various combinations of the two was newly developed for use in running numerical computations.[19]

Vinod Kumar Sharma, et al. (2016) reviewed the effect of inlet manifold geometry and swirl intensity on the direct injection (DI) diesel engine performance was investigated experimentally. Modifications in inlet manifold geometry have been suggested to achieve optimized swirl for the better mixing of fuel with air. The intake swirl intensities of modified cylinder head were measured in swirl test rig at different valve lifts. Later, the overall performance of $435 \mathrm{CC}$ DI diesel engines was measured using modified cylinder head. In addition, the performance of engine was compared for both modified and old cylinder head. For same operating conditions, the brake power and brake specific fuel consumption was improved by $6 \%$ and $7 \%$ respectively with modified cylinder head compared to old cylinder head. The maximum brake power of 9 HP was achieved for modified cylinder head. The results revealed that the intake swirl has great influence on engine performance.[20]

Chang Chun $\mathrm{Xu}$ et al. (2012) have researched the software ANSYS which Computational Fluid Dynamics (CFD) simulation to investigate the influence of the air-fuel swirl with different piston crown shapes inside the combustion chamber of the four-stroke automotive engine. The field flow into the combustion chamber for air-fuel mixing to obtain the air-fuel swirl ratio, combustion rate, and air-fuel combustion efficiency when the air-fuel swirl is appeared in the cylinder. They have studied the influence of fluid flow in the combustion chamber of the piston crown structure by computational fluid dynamics, and the investigation by the CFD code in the intake system and compression strokes, changing the shape of the intake port and the intake port number to increase vortex ratio.[21]

Santhosh Kumar.G et al. (2012) have studied about the effects of air swirl in the cylinder on its performance. Here a single cylinder direct injection diesel engine is used for study. For obtaining different swirl intensities the following design parameters have been changed the piston crown, cylinder head and inlet duct. By changing the piston crown design the enhancement in the turbulence inside the cylinder is achieved. Also grooves are made to achieve the increase in swirl intensity for better mixing of fuel and air. The GP 9 piston crown configuration ie piston with 9 grooves is the best in performance and lower in emission. Due to increase in number of grooves the turbulence is enhanced and hence results in better fuel-air mixing. As GP 9 configuration has more no of grooves its performance is higher when compared to other configurations. Also the thermal efficiency is increased \& SFC and soot emissions are reduced. [22]

\section{CONCLUSION}

Keeping findings in literature in consideration, we proposed the following objectives can be followed for research work.

1. To design various shapes of Cylinder heads.

2. To perform CFD simulations of the designed Cylinder heads of the IC engine.

3. To study the effect of Cylinder head configurations on the in-cylinder air flow (only intake and compression stroke; combustion stroke is not considered.)

4. To compare effect of different cylinder head configurations on volumetric efficiency, turbulence, swirl and tumble ratio in the engine.

5. To know whether the flow is achieving uniform, high quality organized flow in the test section.

6. To also arrive at a shape this will have organized strong turbulence and uniform flow.

\section{REFERENCES}

[1] R Ramachandra, V Pandurangadu, 'Performance Of Ic Engine Based On Swirl Induction By Using CFD', Vol. 5, No. 3, August 2016 ISSN 2319-5991International Journal of Engineering research and Science \& Technology.

[2] Bandi.Ramanjulu, Adissu Fulli, D.Jegan Raj, Abera Endesha Bekele 'Performance Analysis of IC Engine Based on Swirl Induction by Using CFD' Vol. 2, Issue 5 , May 2015 International Journal of Advanced Research in Science, Engineering and Technology. 
[3] K.Raj Kiran, C.G.Saravanana, and Edward James Gunasekarana, 'An Analysis on Effects of Performance, Combustion and Emission for Various Intake Flow in a DI Diesel Engine', Volume 4, Issue 12, December -2017 International Journal of Advance Engineering and Research Development.

[4] Lucas Konstantinoff, Christoph Pfeifer, Martin Pillei, Uwe Trattnig, Thomas Dornauer, Lukas Möltner 'Optimization of the Charge Motion in Sewage Gas-Driven Internal Combustion Engines for Combined Heat and Power Units' Volume 11, 2017 International Journal Of Mechanics.

[5] Pankaj N.Shrirao, Kapil B.Salve, Sachin S. Pente 'Swirl Induction with Dimpled Cylinder Head and its Effect on Exhaust Emission of Diesel Engine', Volume 4 Issue 10, October 2015 International Journal of Science and Research (IJSR).

[6] J Benajes, S Molina, J M Garcı'a and J M Riesco 'The effect of swirl on combustion and exhaust emissions in heavy-duty diesel engines' Proc. Instn Mech. Engrs Vol. 218 Part D: J. Automobile Engineering

[7] H. Mohamed Niyaz1, Prof. A. S. Dhekane 'Twin Helical Intake Port Design Optimization And Validation By Using CFD Analysis' Volume 4, Issue 4, April 2014 , International Journal of Emerging Technology and Advanced Engineering.

[8] M D Raj Kamal, S.Kaliappan, S.Socrates, G.Jagadeesh Babu 'CFD Analysis of Single Cylinder IC Engine Inlet Swirl Valve' Volume - 02, Issue - 08, August - 2017, International Journal of Latest Engineering Research and Applications (IJLERA) ISSN: 2455-7137 PP - 34-46.

[9] Zhen Lu, TianyouWang, Xincai Li, Liting Li and Guoyong Zhang, 'Parametric design of the tangential intake port in diesel engines', Journal of Automobile Engineering.P No 409-420.

[10] Arjun Garg, Karan Garg 'Optimization Of Piston Head Of Single Cylinder Diesel Engine' March, 2017 International Journal of Engineering Sciences \& Research Technology.

[11] Jorge MARTINS, Senhorinha TEIXEIRA Stijn COENE , 'Design Of An Inlet Track Of A Small I. C. Engine For Swirl Enhancement' 15-20, 2009, International Congress of Mechanical Engineering November Gramado, RS, Brazil.

[12] K Vijaya Kumar , Damera Babitha K Srinivasa Raghavan and P Shailesh Sunchu, Abhishekaran, Sunchu Anusthitha, 'Investigation of Diesel Engine Performance with Design Modifications in Piston: Inducing Turbulence by Swirl' Vol. 7, No. 5, September 2018 International Journal of Mechanical Engineering and Robotics Research.

[13] Ujwal D. Patil, 'Cylinder Head Intake Port Design \& In-Cylinder Airflow Patterns, Streamlines formations, Swirl Generation Analysis to
Evaluate Performance \& Emissions' International Journal of Engineering Research \& Technology (IJERT) Vol. 2 Issue 9, September - 2013

[14] V M Latheesh, P Parthasarathy, V Baskaran and S Karthikeyan, 'Design and CFD analysis of intake port and exhaust port for a 4 valve cylinder head engine' IOP Conference Series: Materials Science and Engineering.

[15] Bharani Dharan R, S S Ramdasi and Neelkanth Marathe, 'Design / Analysis and Development of Cylinder Head for High Performance 3 Cylinder CRDi Euro-V Diesel Engine for a High Combustion Pressure of 200 Bar' SAE International by Univ of California Berkeley.

[16] Kunjan Sanadhya, N. P. Gokhale, B.S. Deshmukh, M.N. Kumar, D.B. Hulwan , 'Effect of Helix Parameter Modification on Flow Characteristics of CIDI Diesel Engine Helical Intake Port' Vol. 4, Issue 4, April 2015, International Journal of Innovative Research in Science, Engineering and Technology.

[17] Kumar P. Shaha, Ankush R. Yadav, Sameer V. Shinagare, Rakesh V. Zirpe, Ganesh Suryawanshi, 'Design of Test Rig for Swir Measurement in I.C. Engine', Vol. 4, Issue 12, 2017, International Journal for Scientific Research \& Development.

[18] Shuisheng JIANG, Siwei ZHU, Hua WEN, Shuping HUANG 'Parameter Analysis of Diesel Helical Intake Port Numerical Design' International Conference on Future Energy, Environment, and Materials, Elsevier.

[19] Jun-ichi Kawashima, Hiroshi Ogawa and Yoshiyuki Tsuru' ' Research on a Variable Swirl Intake Port for 4-Valve High-Speed DI Diese Engines' International Fall Fuels and Lubricants Meeting and Exposition San Francisco, California, October 19-22, 1998.

[20] Vinod Kumar Sharma, Man Mohan and Chandra Mouli, ' Effect of intake swirl on the performance of single cylinder direct injection diesel engine' IOP Conf. Series: Materials Science and Engineering 263 (2017) 062077

[21] Chang Chun Xu and Haeng Muk Cho , 'The Analysis of the CFD about the Swirl Generation in Four- Stroke Engine' Volume 11, Number 16 (2016) International Journal of Applied Engineering Research ISSN 0973-4562, pp 8940-8945

[22] Santhosh Kumar.G ,Prof.K.Hema Chandra Reddy , Ch.Rajesh , G.Suresh Kumar 'A Review On Study Of The Effect Of In Cylinder Air Swirl On Diesel Engine Performance And Emission' International Journal of Recent advances in Mechanical Engineering (IJMECH) Vol.1, No.2, November 2012. 